\title{
APORTACIONES DEL GRABADO EUROPEO AL ARTE EN GUATEMALA
}

\section{Por Ricardo Toledo Palomo}

EL ESTUdio de los grabados europeos y su cotejo con las obras salidas de los talleres de los artistas de América, nos deparan grandes sorpresas, pues pinturas y esculturas, que por mucho tiempo fueron consideradas como producto de una inventiva propia de los artistas americanos, no son en realidad sino copias tomadas de estampas ultramarinas. Por ello hay que apreciar la verdadera significación que tiene esta clase de inves. tigaciones para adentrarse en la comprensión de nuestro arte, ya que al estudiar las fuentes primigenias y compararlas con las formas derivadas de ellas, podemos averiguar no sólo la difusión que alcanzan las obras del viejo continente en el nuestro, sino también obtener un mejor conocimiento de las predilecciones estéticas y temáticas en esa etapa de la actividad artística americana.

Conociendo la incidencia del grabado europeo en las realizaciones de nuestros artistas, también se demuestra el mayor o menor grado de originalidad o de sujeción de éstos a los patrones de ultramar. Algunas pinturas y esculturas copian fielmente las muestras extranjeras, siguiendo sin reserva a los modelos; en otras obras, en cambio, se toman sólo ciertos elementos para combinarlos con formas originales. En estos últimos casos es más difícil llegar a reconocer sus antecedentes, ya que los artistas componian sus trabajos con base en varias estampas, tomando ideas de unas y otras, o bien transformando, acondicionando y corrigiendo los elementos de las mismas con aportaciones de su propia cosecha.

Grabados de pinturas flamencas, de obras del centro de Europa, de Italia y de España, llegan desde tempranas fechas y fue por este medio como se dio a conocer el mensaje del arte universal en América y fue también de esta manera como puieron influir con más facilidad y en forma más decisiva las corrientes artísticas occidentales en las obras de nuestros artistas.

Las copias en grabado de pinturas de artistas del Renacimiento como Miguel Ángel, Rafael o Leonardo; las copias de obras de Rubens y Van Dyck, así como las estampas de lienzos de Caravaggio y de Ribera, los grabados de Durero, de Martín de Vos, de Schongauer, de Cornelio 
Galle, de los Sadeler..., fueron especiales motivos de inspiración que los artistas americanos recibieron para realizar sus trabajos. Pero no sólo las obras de los grandes representativos del arte occidental fueron utilizadas: también se aprovechaban grabados anónimos y láminas comunes, así como estampas sueltas o ilustraciones existentes en las páginas de los libros.

Esa aportación decisiva de las estampas europeas no fue recibida solamente por los pintores e imagineros; también los arquitectos se dejaron seducir, al realizar sus obras bajo esa influencia; igual cosa se observa en los trabajos de artes menores, ejecutados en los talleres de grabadores, plateros, carpinteros y ensambladores.

La bibliografía existente sobre este tema cuenta ya con abundante material de consulta. Varios historiadores y críticos de arte han dedicado estudios monográficos a este asunto; entre éstos deben señalarse los de Diego Angulo fñiguez: Algunas huellas de Schongauer y Durero en Méjico, ${ }^{1}$ Pereyns y Martín de Vos: El retablo de Huejotzingo; ${ }^{2}$ el trabajo de Justino Fernández sobre Rubens y José Juárez; ${ }^{3}$ el de Antonio de la Banda y Vargas: La influencia de un grabado sevillano en las pinturas del coro del convento de las Teresitas en Querétaro; 4 el de Martín Soria: Una nota sobre pintura colonial y estampas europeas; 5

1 Diego Angulo lñiguez, "Algunas huellas de Schongauer y Durero en Méjico", Archivo español de arte, Consejo Superior de Investigaciones Cientificas, Instituto Diego Velázquez, 72, Madrid, 1945, p. 382. Francisco de la Maza publicó unas notas criticas a este articulo en Anales del Instituto de Investigaciones Estéticas, UNAM, Iv, 15, México, 1947, pp. 118-119.

2 Diego Angulo tñiguez, "Pereyns y Martín de Vos: el retablo de Huejotzingo", Anales del Instituto de Arte Americano e Investigaciones Estéticas, Facultad de Arquitectura y Urbanismo, Universidad de Buenos Aires, 2, Buenos Aires, 1949, pp. 25-27.

3 Justino Fernández, "Rubens y José Juárez", Anales del Instituto de Investigaciones Estéticas, UNAM, III, 10, México, 1943, pp. 51-57.

4 Antonio de la Banda y Vargas, "La influencia de un grabado sevillano en las pinturas del coro del convento de las Teresitas en Querétaro", Anuario de estudios americanos, Escuela de Estudios Americanos, sección de Historia de América de la Universidad de Sevilla, Consejo Superior de Investigaciones Científicas, xvi, Sevilla, 1959, pp. 553-560.

5 Martin Soria, "Una nota sobre pintura colonial y estampas europeas", Anales 


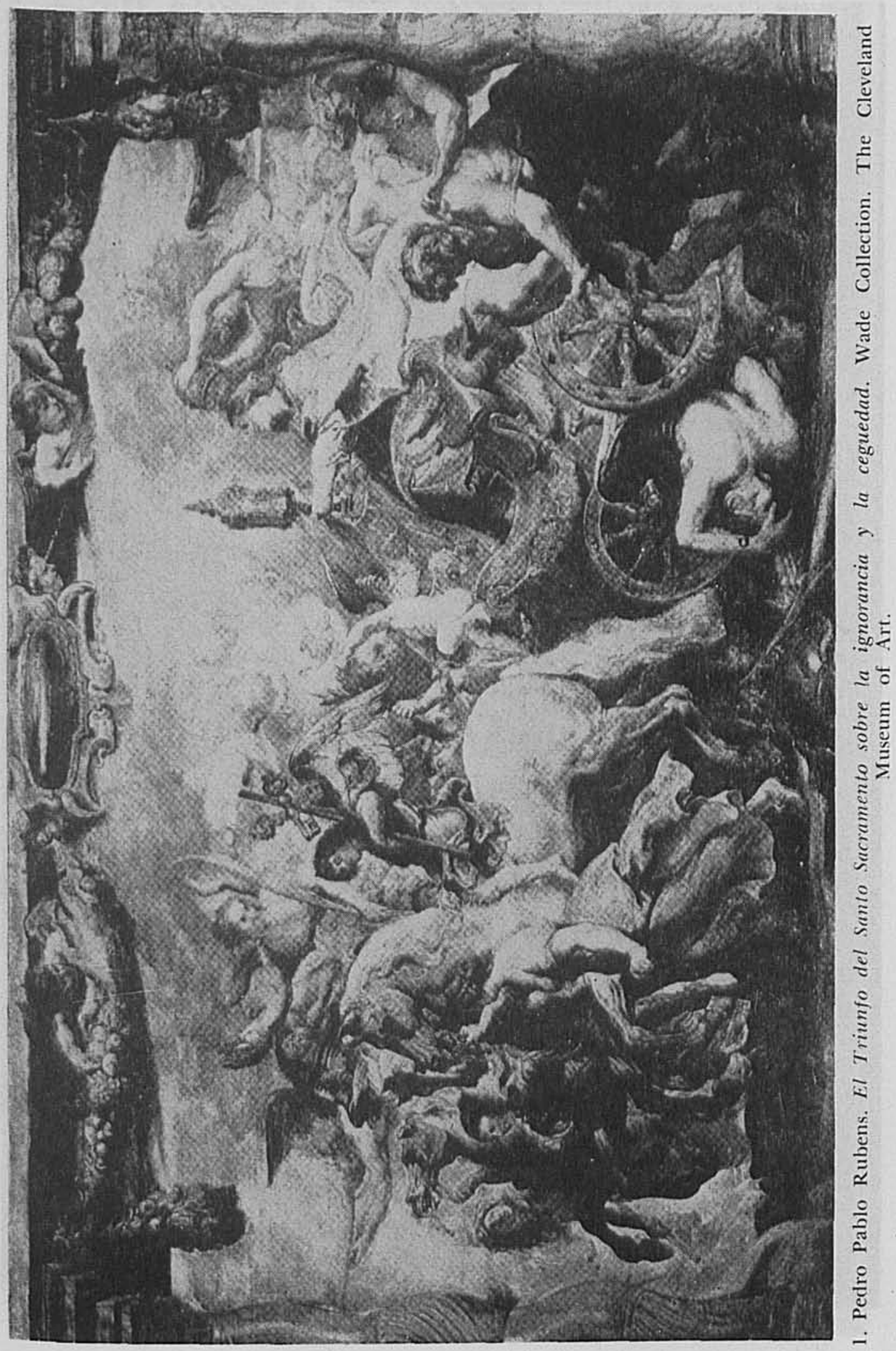


DOI: http://dx.doi.org/10.22201/iie.18703062e.1966.35.819

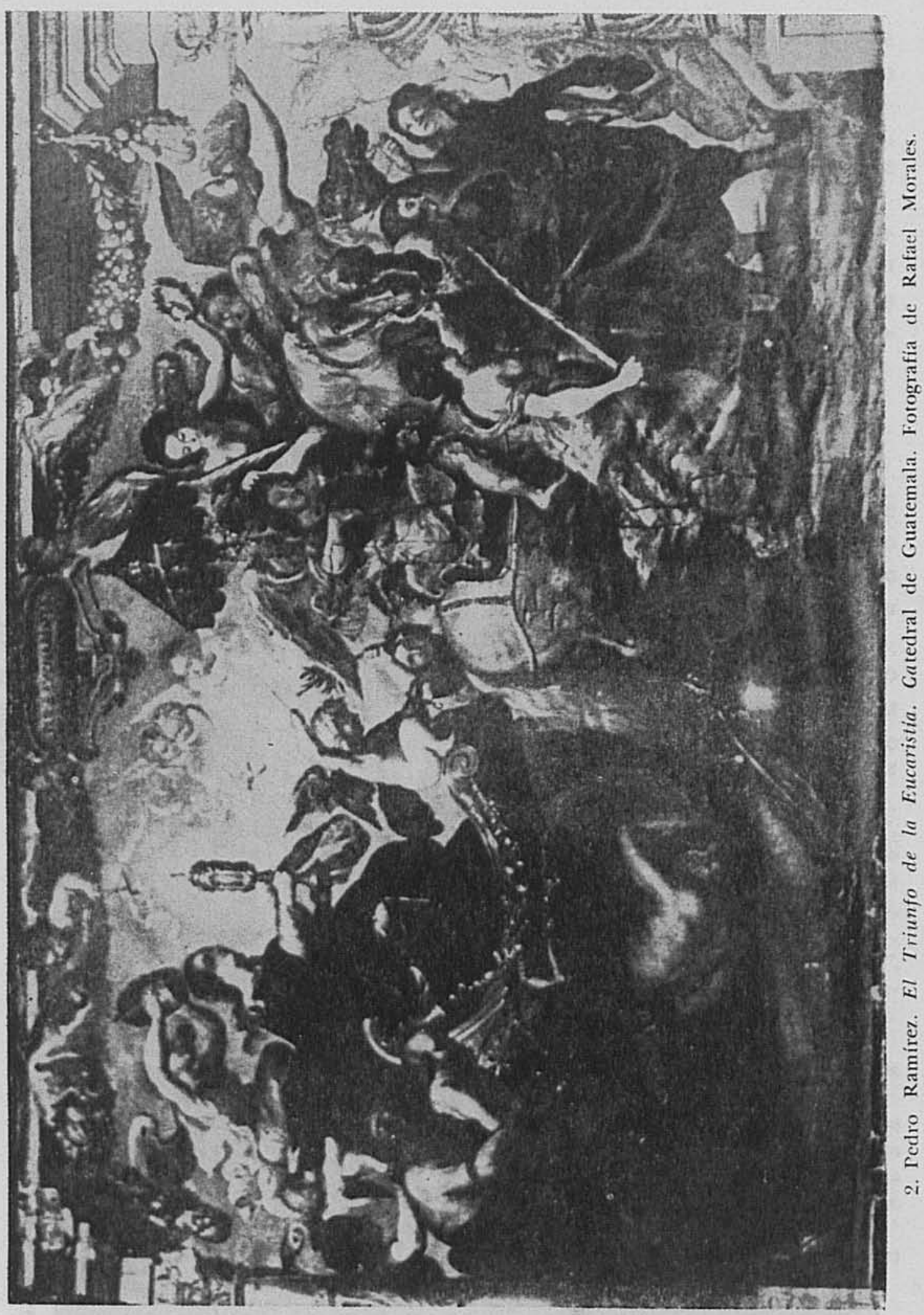




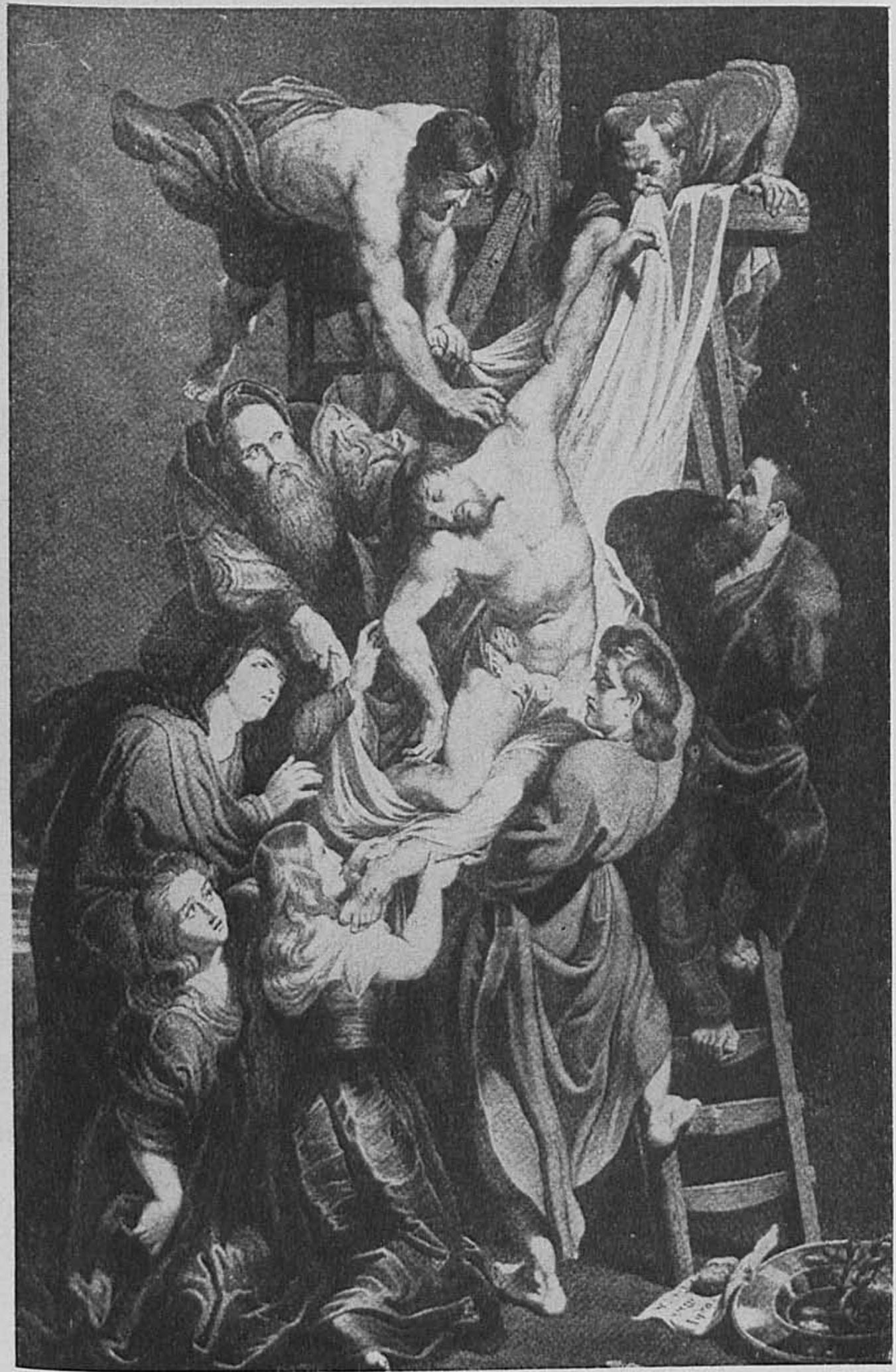

3. Pedro Pablo Rubens. El Descendimiento de la Cruz. Catedral de Amberes. Grabado de autor desconocido. 


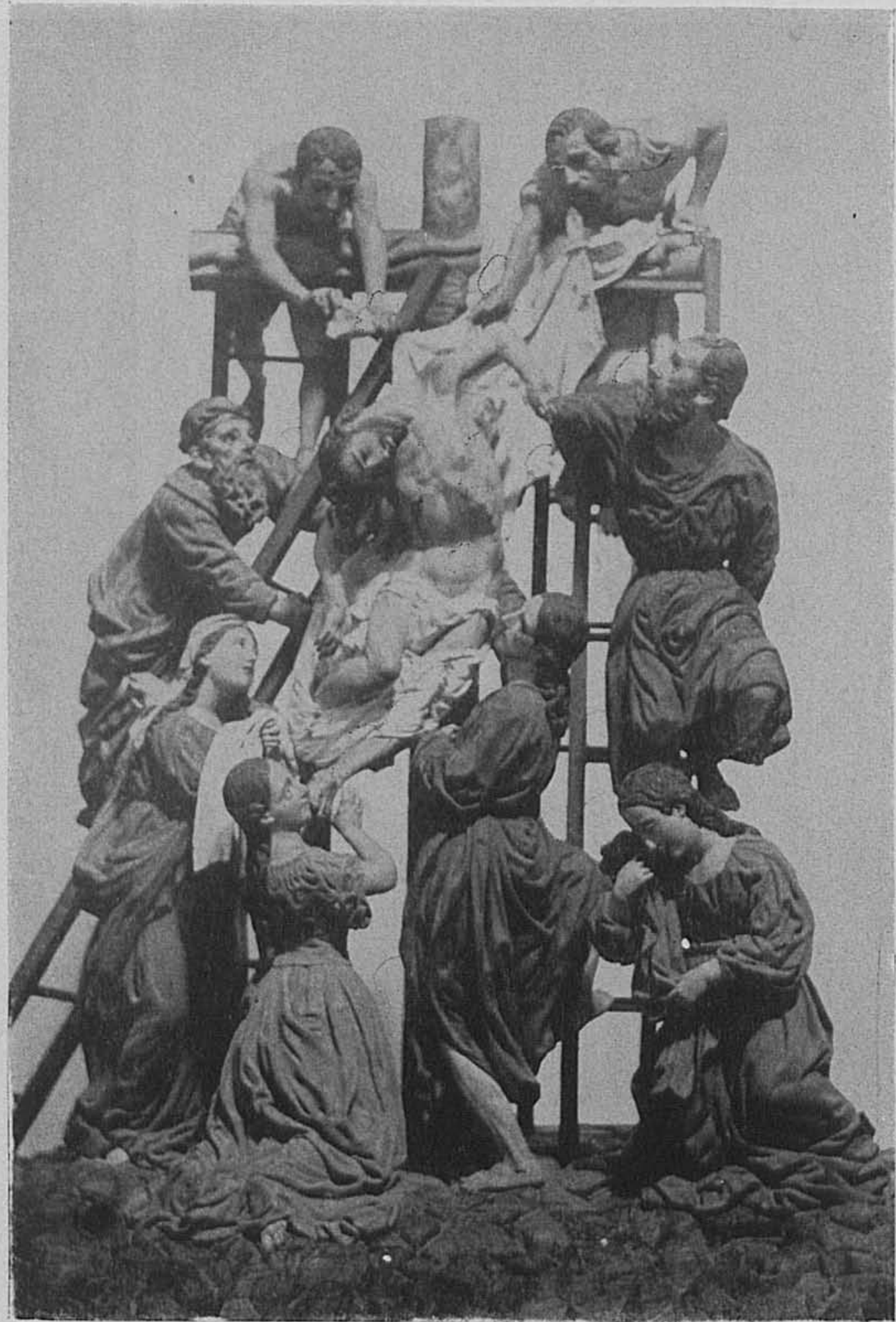

4. Anónimo. El Descendimiento de la Cruz. Iglesia de la Merced. Guatemala. Fotografia del autor. 


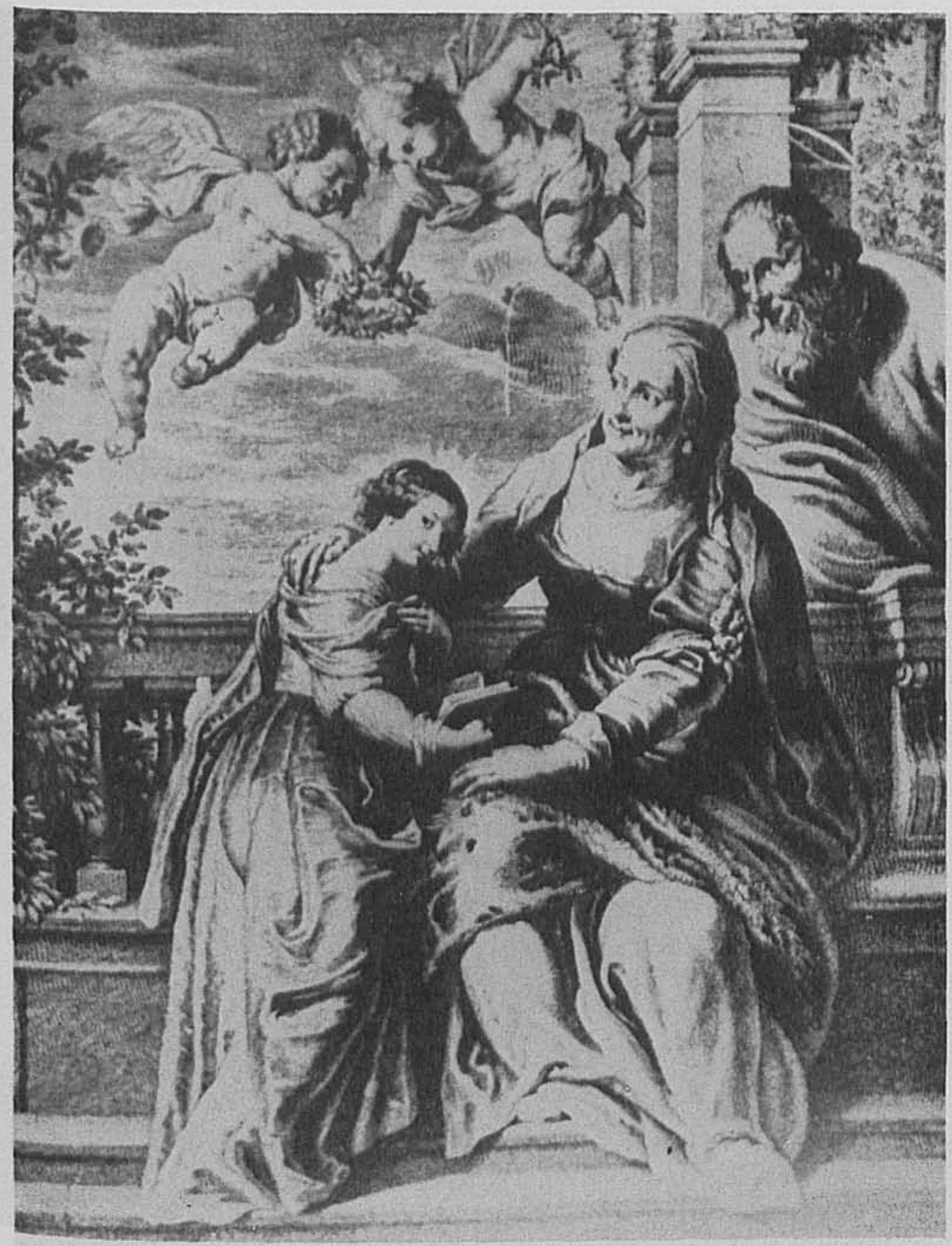

5. Pedro Pablo Rubens. La Virgen Maria y Santa Ana. Grabado de Schelte de Bolswert. 


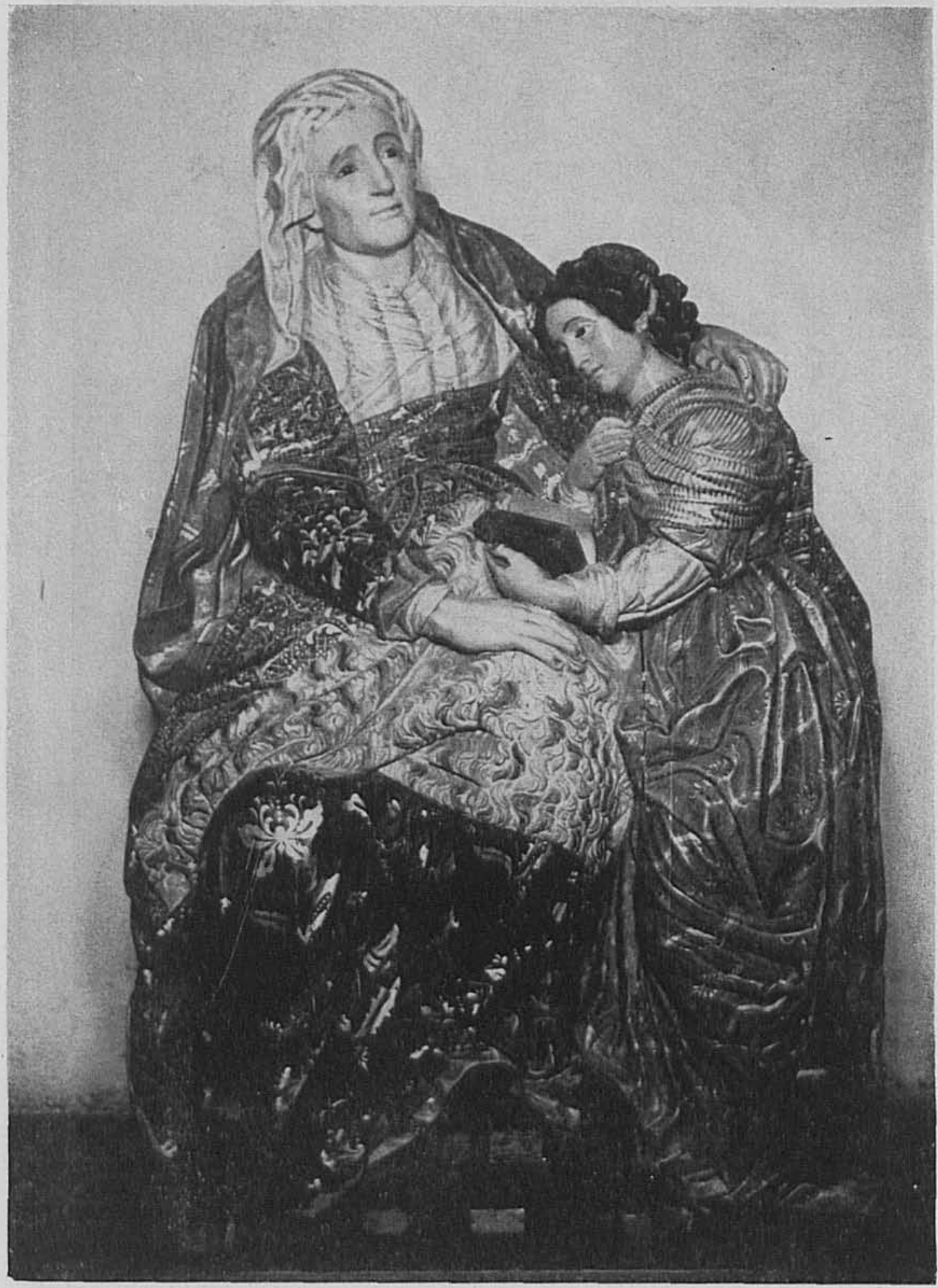

6. Anónimo. La Virgen Maria y Santa Ana. Iglesia de Santo Domingo. Guatemala. Fotografía de fray Luis Maria Estrada Patteau, O. P. 
DOI: http://dx.doi.org/10.22201/iie.18703062e.1966.35.819

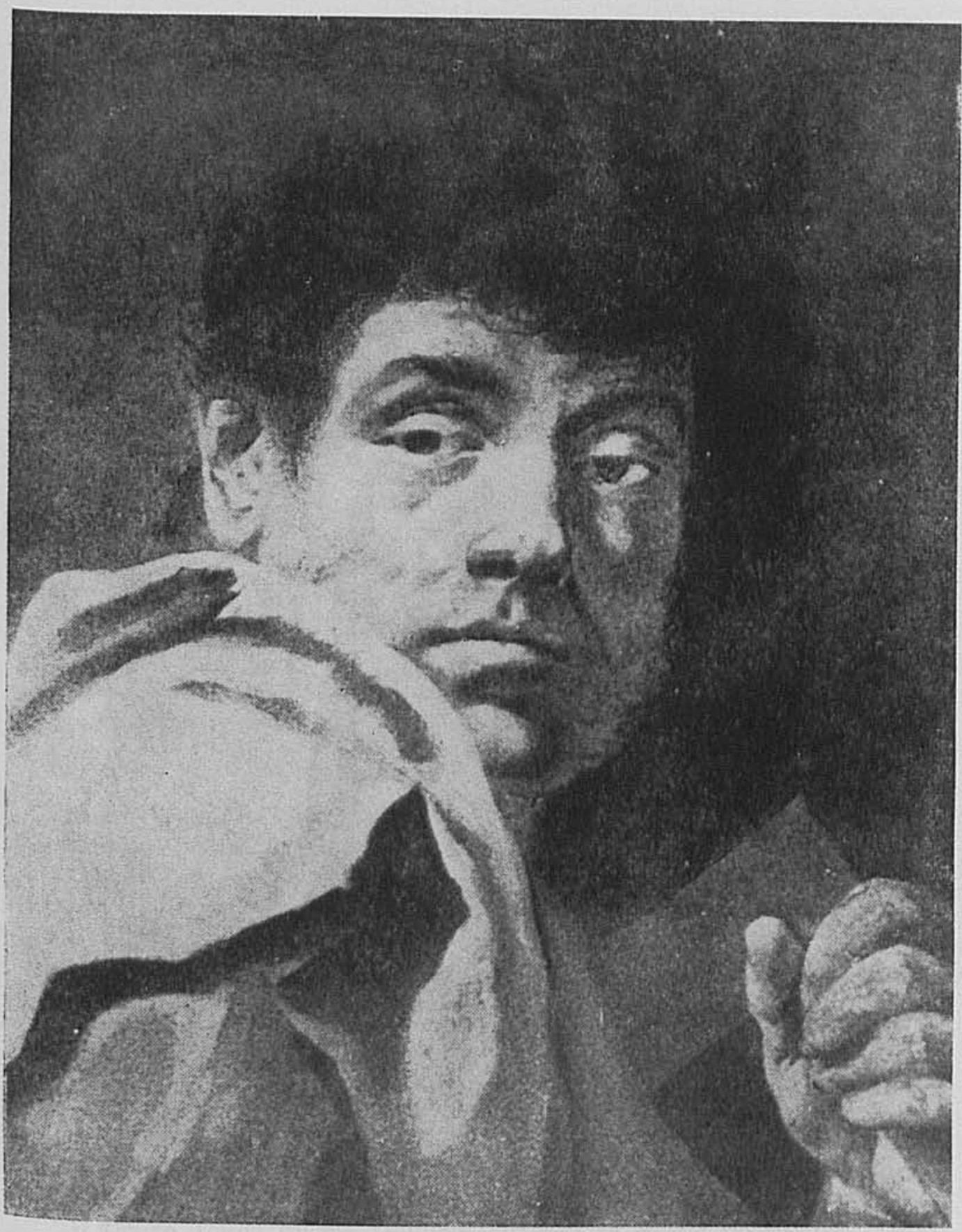

7. Juan Bautista Piazzeta. San Judas Tadeo. 


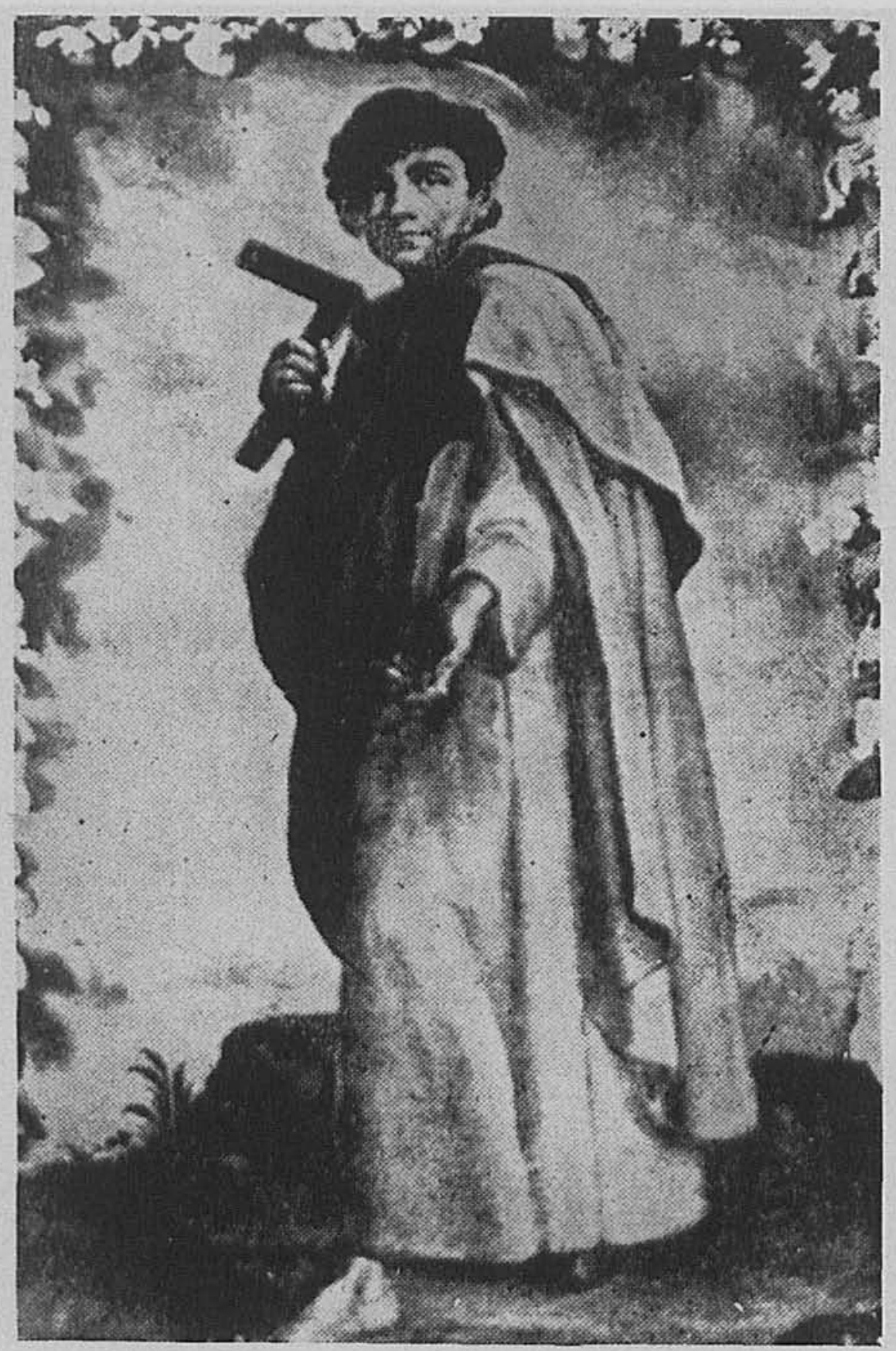

8. José Valladares. San Judas Tadeo. Iglesia de la Merced. Guatemala. 
el de Gibson Danes: Baltasar de Echave Ibia, some critical notes on the stylistic character of his art, " y entre los más recientes el de Santiago Sebastián: Pinturas derivadas de grabados en Cali, 7 y el de Xavier Moyssén: Tecamachalco y el pintor indigena Juan Gersón. ${ }^{8}$

En el caso particular del arte en Guatemala, también se han hecho referencias directas sobre el empleo de estampas. Entre los estudios que pueden citarse encuéntranse los realizados por Pál Kelemen ${ }^{9}$ y Enrique Berlin, ${ }^{10}$ a los que hay que agregar un trabajo dedicado a señalar la influencia del grabado francés en el arte desarrollado en Gautemala durante el siglo xvir. 11

Desde tempranas épocas se proporcionan en las crónicas coloniales. algunas noticias en las que se indica la participación decisiva del grabado en la enseñanza de las artes. Fray Toribio de Benavente, el célebre Motolinia, nos dice que los indígenas "han salido grandes pintores después que vinieron las muestras e imágenes de Flandes y de Italia que los Españoles han traido, de las cuales han venido a esta tierra muy ricas piezas..." 12

Similar referencia anota tiempo después, a principios del siglo xvII, el cronista de la orden seráfica de Guatemala, fray Francisco Vázquez: “... los mismos indios se aplicaban a pintar y esculpir santos o ya copiándolos de alguna estampa, o en la forma que se les decía y como eran

del Instituto de Arte Americano e Investigaciones Estéticas, Facultad de Arquitectura y Urbanismo, Universidad de Buenos Aires, 5, Buenos Aires, 1952, pp. 43-49.

- Gibson Danes, "Baltasar de Echave Ibia, some critical notes on the stylistic character of his art", Anales del Instituto de Investigaciones Estéticas, UNAM, II, 9, México, 1942, pp. 15-26.

7 Santiago Sebastián, "Pinturas derivadas de grabados en Cali", Anales del Instituto de Investigaciones Estéticas, UNAM, 33, México, 1964, pp. 41-43.

8 Xavier Moyssén, "Tecamachalco y el pintor indigena Juan Gersón", Anales der Instituto de Investigaciones Estéticas, UNAM, 33, México, 1964, pp. 23-39.

- Pál Kelemen, Baroque and Rococo in Latin America, the MacMillan Co., New York, 1951.

10 Enrique Berlin, Historia de la imagineria colonial en Guatemala, Publicaciones del Instituto de Antropologfa e Historia de Guatemala, Editorial del Ministerio de Educación Pública, Guatemala, CA, 1952.

i1 Ricardo Toledo Palomo, "Influencia francesa en el arte guatemalteco", Antropologia e historia de Grtatemala, Publicaciones del IDAEH, XIv, 2, Guatemala, 1962, pp. 66-73.

12 Fray Toribio de Benavente o Motolinia, Historia de los indios de la Nueva España, edición de fray Daniel Sánchez García, Herederos de Juan Gili, Barcelona, 1914 , p. 216. 
obras más de afición al arte quc de inteligencia de él, salfan tan disformes algunas." 13

También con la ayuda de documentos se puede probar esa contribución de las estampas al arte colonial de Guatemala. Algunas noticias a ese respecto existen en los libros de protocolos de escribanos y en otras fuentes documentales, principalmente, en las escrituras que se refieren a contratos de obras, y en los testamentos. e inventarios de bienes; en los contratos se señala directamente el empleo de láminas en determinadas obras, mientras que en los otros documentos se mencionan colecciones de estampas que fueron propiedad de los artistas.

En un contrato del siglo xvir, los escultores Quirio Cataño y Antón de Rodas se obligan a hacer un retablo para Sonsonate, El Salvador; en el documento se indica:

Iten se encargan de hacer un retablo de meida talla de relieve para poner a la mano derecha del Sacramento de San José que vaya hacia el arca y traiga de la mano el niño Jesús como anda en las estampas suyas..."

En el mismo contrato se anota:

Iten se encargan de hacer un compartimiento o tarjeta en que estén tallados o relevados los dos brazos de Cristo y de San Francisco cruzando como se suelen pintar particularmente en la estampa que se trajo de Roma en la bula de la indulgencia que se gana el día de San Francisco con una cruz en medio... ${ }^{14}$

En el juicio testamentario de doña Isabel de Colindres Puerta, viuda del pintor don Antonio de Montúfar (1627-1668), se lee en una de las cláusulas:

Iten mando que den a don Francisco Antonio de Montúfar, mi hijo... cinco escritorios, uno en que están los papeles que me tocan, otro lleno de estampas. ${ }^{15}$

También entre los bienes de la mortual del maestro pintor don José de Victoria, fallecido en 1716, se menciona un libro de estampas. ${ }^{16}$

13 Fray Francisco Vázquez, Crónica de la provincia del Santisimo Nombre de Jest́s de Guatemala, Biblioteca "Goathemala" de la Sociedad de Geografía e Historia de Guatemala, xv, II, Guatemala, CA, 1988, p. 228.

14 Berlin, op. cit., pp. 190-191.

15 Archivo General del Gobierno, Guatemala. Documento: Al-43, 17571, 2340, Año de 1684 .

16 Berlin, op. cit., p. 41 . Véase también Archivo General del Gobierno, Guatemala. Documento: Al-49, 42482, 4995. Año de 1716. 
El último influjo del grabado europeo durante los años coloniales lo encontramos con el establecimiento de la Escuela de Dibujo, patrocinada por la Sociedad Económica. Bajo las severas reglas académicas que propicia la Escuela se considera beneficioso a los alumnos, el empleo de grabados que reproducen las obras de los grandes maestros. La Gazeta de Guatemala informa de esas actividades en los artículos que describen las distribuciones de premios y las exhibiciones que realizaba la Escuela de Dibujo; alli se menciona que se había reproducido un cuadro que representaba a Santa Cecilia de una copia del original de Giovanni Francesco Barbieri llamado "El Guercino", asi como que otra obra se había inspirado en la Armonía de Angélica Kauffman; también se había copiado según indica una breve referencia, una obra de Miguel Angel que representaba a Moisés con las tablas de la ley. Todos estos trabajos los había realizado el alumno Francisco Rendón. EI Niño Dormido, obra del primer director de la Real Academia de San Fernando de Madrid, el pintor italiano Jacopo Amigoni, había servido para una pintura del alumno Guillermo Estrada. Narciso Rosal sigue un grabado de Jean Bautiste Greuze que representa al Padre de Familia leyendo la Biblia, y según la descripción es muy probable que de un original del mismo artista, José Casildo España había copiado La Madre Feliz. ${ }^{17}$

Como es de suponerse, los retratos de personajes reales toman como base los grabados; es así como se hace mención que de un grabado de Carnicero, que ilustra una traducción española del poema "Las esta. ciones" de Thomson, se había copiado el retrato de Fernando VII. ${ }^{18}$ El pintor Juan José Rosales copia un retrato del mismo personaje tomando como modelo los grabados de Rico y Brunetti, basados en el diseño de Antonio Carnicero; esta pintura fue utilizada para la Jura del Rey. ${ }^{19}$

Fuera de esas menciones existentes en impresos coloniales se ha podido señalar con precisión el antecedente de algunas obras de esa época, tal el caso de la pintura El llanto de los ángeles que Juan José Rosales (.......-1816) copia de un original de Charles Le Brun, y un grabado de Hércules y la Hidra de Lerna por Francisco Cabrera (1781-1845), que reproduce una estampa de Bernard Picart. ${ }^{20}$

17 Gazela de Guatemala, v 221-226, 555-575, 1801.

18 Gazeta de Guatemala, XI, 47, 368, 1809.

19 Guatemala por Fernando Séptimo el dia 12 de Diciembre de 1808, p. 46.

20 Toledo Palomo, op. cit., véase ilustraciones. 
La última parte de este trabajo la dedicamos a buscar la relación de algunas pinturas y obras de imaginería de la época colonial, existentes en colecciones guatemaltecas, con sus antecedentes europeos. Al mismo tiempo de enumerar y clasificar las copias guatemaltecas deseamos vincularlas con obras de otras regiones de América, que siguen los mismos modelos, lo cual demuestra que esa relación no es un caso aislado. Para ello reunimos en un solo cuerpo las menciones que proporcionan los autores citados, agregando a los datos ya conocidos, nuevas aportaciones que harán comprender la importancia que tiene el grabado europeo para identificar las raíces aprovechadas en algunas obras del periodo colonial.

Iniciamos nuestro recorrido haciendo mención de algunas copias de las obras de Pedro Pablo Rubens (1577-1640). Él es, entre los artistas europeos, quien más modelos proporciona. Esa predilección por la obra de Rubens es más notable durante el periodo barroco. Un escritor que se dedicó al estudio del arte de Guatemala, don Jesús Fernández, en la serie de artículos que publicó en La Semana Católica, hace importantes referencias al mismo, y cuando describe las grandes composiciones de Pedro Ramírez, existentes en la iglesia catedral, nos indica que son copias. ${ }^{21}$ Posteriormente Enrique Berlin en su estudio "Pintura colonial mexicana en Guatemala", aclara que Ias obras pertenecen al pintor novohispánico Pedro Ramírez, y que una de ellas se encuentra firmada y fechada en 1673; al mismo tiempo adiciona un dato, por información proporcionada por José Mata Gavidia, indicando que los dos lienzos del pintor mexicano son copias del Triunfo de la Iglesia y del Triunfo sobre la Adoración Pagana, tomadas de originales de Rubens. ${ }^{22}$ Estos dos lienzos copian los cartones sobre temas eucarísticos de la colección que Rubens ejecutó para los tapices con los que la infanta Clara Eugenia, deseaba obsequiar al convento de las Descalzas Reales de Madrid y que fueron grabados posteriormente por Schelte de Bolswert. Existen

21 Jesús Fernández, "Estudios sobre la exposición", La Semana Católica, v, 261, Guatemala, 1897, p. 415. Véase también "Los estudios sobre la exposición de don Jesús Fernández", introducción y notas por Ricardo Toledo Palomo, Anales de la Sociedad de Geografia e Historia de Guatemala, xxxir, 1-4, Guatemala, 1959, pp. 121122.

22 Enrique Berlin, "Pintura colonial mexicana en Guatemala", Anales de la Sociedad de Geografia e Historia de Guatemala, xxvi, I, Guatemala, 1952, pp. 121-122, láminas en pp. 120-121. 
entre las obras de los artistas americanos otras copias basadas en estos temas; de ellas cabe mencionar las alegorias del Triunfo de la Iglesia en la sacristía de la catedral de Puebla, pintadas por Baltasar de Echave Rioja (1632-1682), ${ }^{23}$ y las que ejecutó Cristóbal de Villalpando copiando el mismo asunto en la catedral de Guadalajara. Otras obras de este último pintor inspiradas en estos temas de Rubens son las dos telas de dimensiones mayores, existentes en la sacristía de la catedral de México, ejecutadas alrededor de 1684-85. ${ }^{24}$ En el Perú es conocida una pintura mural del Triunfo de la Eucaristia, en la iglesia de la Asunción de Azángaro. ${ }^{25}$ Otro ejemplo aparece en la iglesia catedral de Huamanga.

Una de las pinturas más conocidas de Rubens es la famosa y movida composición del Descendimiento de la Cruz, existente en la catedral de Amberes; de ella es conocida una copia hecha por el grabador Lucas Vostermann, y es posible que siguiendo ese grabado, se haya pintado el lienzo que aparece en el remate de un retablo de la iglesia del convento de monjas Gapuchinas en la Nueva Guatemala. ${ }^{27}$ El doctor Enrique Berlin nos informó sobre dos pinturas del mismo tema que se conservan en la iglesia parroquial y en el Calvario de Tecpan, Guatemala, respectivamente. 28

También este mismo motivo se observa reproducido en la cima del retablo del Cristo llamado de Salamé, en la catedral de Comayagua, Honduras. En la iglesia de la Merced en la Nueva Guatemala, sobresale una pequeña talla de este tema; esta traducción en escultura de tamaño menor, parece corresponder a los años finales del xviII o primeros del siguiente siglo.

Otra copia de un original de Rubens es la pintura de El Martirio de

23 Pedro Rojas, Historia general del arte mexicano, época colonial, Editorial Hermes, S. A., México, 1963, p. 192.

24 Abelardo Carrillo y Gariel, Técnica de la pintura en la Nueva España, UNAM, Instituto de Investigaciones Estéticas, Imprenta Universitaria, México, 1946, pp. 157. 158, láminas 48-49. Agustín Velázquez Chávez, Tres siglos de pintura colonial mexicana, Editorial Polis, México, 1939, pp. 270-272, figura 93. Rojas, op. cit., p. 195.

25 Ricardo Mariátegui Oliva, Iglesia de la Asunción de Azángaro, II, documentos de arte peruano, publicaciones del Instituto de Investigaciones de arte peruano $y$ americano, Lima, Perú, 1948, p. 26, lámina xI.

26 Ibidem, nota en p. 26.

27 Enrique Berlin hace mención de esa pintura en su artículo "Baroque and Rococo in Latin America, Pál Kelemen, New York, 1951", Anales de la Sociedad de Geografia e Historia de Guatemala, xxv, 4, Guatemala, 1951, p. 420.

28 Datos proporcionados al autor por el doctor Enrique Berlin. 
San Lorenzo, en un retablo barroco de la iglesia de la Merced en la ciudad capital de Guatemala. El lienzo copia un original del maestro holandés que se conserva en la Pinacoteca Antigua de Munich, Alemania. La confrontación de las reproducciones de la obra original con la pintura existente en Guatemala indica que esta última se encuentra totalmente invertida en relación a la composición original, regla común en las obras basadas en los grabados. Angulo fñiguez informa sobre una copia similar atribuida al pintor Juan Bautista Vázquez, en la iglesia de las Nieves en Bogotá, Colombia. ${ }^{29}$

Tomada de un original de Rubens, grabado posteriormente por Schelte de Bolswert, es la singular escultura de Santa Ana y la Virgen, de escuela guatemalteca, en madera enriquecida con viva policromía, actualmente en un altar de la iglesia de la orden dominica en la ciudad de Guatemala. La versión guatemalteca evita lo accesorio para dedicarse solamente al tema central. En la talla no aparece la figura de San Joaquín, así como faltan los detalles que acompañan al original y al grabado, tales como los angelillos y también la arquitectura, presentando solamente a la Virgen María y a Santa Ana. Esta copia en bulto es una de las obras de mayor interés para mostrar un ejemplo de copia de grabados europeos en nuestra imaginería. La talla en perfecta realización del estofado, técnica que diera tanta fama a Guatemala, tiene en este caso su equivalente en una versión en superficie plana, que copia el mismo grabado ejecutada en la manera de pintura brocateada, que caracteriza a la escuela de pintura cuzqueña. Este último lienzo. existente en La Paz, lo relaciona Soria con el original de Rubens y la copia de Bolswert. El mismo autor señala que el pintor español Pedro Atanasio Bocanegra (1635-1688) ejecutó una obra semejante que hoy se conserva en una colección particular de Barcelona. ${ }^{30}$

También como copia de un pintor flamenco, en este caso de Antonio Van Dyck (1599-1641), Pál Kelemen señala un lienzo que representa a San Sebastián socorrido por un ángel, existente en la catedral de Cuzco, Perú, y una tabla en relieve de la capilla dedicada a dicho santo en la catedral de León en Nicaragua. Kelemen advierte que ambas

29 Diego Angulo Iñiguez, Historia del ärte hispano americano, II, Salvat Editores, Barcelona, 1950, p. 455, figura 411.

30 George Kubler y Martín Soria, Art and Architecture in Spain and Portugal and their american dominions. 1500-1800, Pelican History of art, Baltimore, 1959, p. 234, figuras en p. 178. 
obras proceden de una pintura de Van Dyck en Schelle, Holanda. ${ }^{3 x}$ Enrique Berlin encontró en Guatemala un lienzo de la colección del Palacio Arzobispal, que guarda semejanza con las obras citadas. El origen indicado por Kelemen le sugiere ciertas dudas.

Es posible -dice Berlin- aunque la postura del santo y el ángel son completamente diferentes. En cuanto al último -el de Guatemala-, el cambio experimentado de un extremo del Atlántico al otro no es de peso. La transformación del ángel se explica fácilmente por ideas distintas respecto al pudor angelical y juvenil: el flamenco rubicundo de alegre desnudez se convierte en un joven serio honestamente vestido, ingenuo auxiliador todavía en el relieve de León y hierático preciosista en el cuadro de Cuzco. Pero el criterio de pudor no es suficiente para explicar el cambio de postura del santo, similar en las dos obras americanas, pero muy diferente en el cuadro de Van Dyck. ${ }^{82}$

Además de la actitud diferente del ángel que señala Berlin, debe anotarse la extraña posición del mártir que no concuerda en un todo con el original que señala Kelemen. Consideramos más admisible que todas estas versiones americanas procedan de otro origen, tal vez de una pintura desconocida de Van Dyck, o acaso de una copia en estampa que modificó las actitudes del lienzo de Schelle. Otra pintura de San Sebastián, por Van Dyck, existe en el Museo de El Ermitage, en Leningrado. La afinidad entre este ejemplar y el de Schelle es notoria, aun después de señalar algunas diferencias, principalmente en la actitud y edad del ángel, así como en el tratamiento de los vuelos de las vestiduras.

Pál Kelemen señala como antecedente de una escultura en madera policromada de San Jerónimo, que se encuentra en la sacristía de la iglesia catedral de la ciudad de Guatemala, un grabado que Justus Sadeler hiciera basado en una pintura de Jacopo Palma "El Viejo" (1480-1528) . La escultura existente en Guatemala, es un bello ejemplar de modelado desnudo y de vigorosa anatomía, que muestra al asceta en actitud de meditación, con un libro abierto. De ella dice Kelemen que se ha traducido en tres dimensiones el grabado de Sadeler, y la pintura al óleo de Palma, agregando que el león que aparece a sus pies muestra una cara humana, en una concepción popular que hace

81 Kelemen, op. cit., p. 108, plate 58 d, y Appendix plate 190 g.

32 Berlin, Historia de la imagineria..., p. 60, figuras 24-25. 
que la fiera se aleje de la realidad. ${ }^{33}$ Una pequeña pintura popular sobre lámina de metal en un retablo de la iglesia de la Merced en la Nueva Guatemala, trata el mismo asunto, con un lenguaje ingenuo. Santiago Sebastián identifica una obra análoga a esta guatemalteca en otra pequeña pintura arcaizante de la colección Barona de Cali, Co1ombia. ${ }^{34}$

Entre las obras que conserva la catedral de Comayagua, Honduras, existe un lienzo sobre el Martirio de San Bartolomé, el cual deriva de un grabado del mismo asunto ejecutado por Jusepe Ribera, "El Españoleto" (1598-1656). El grabado original del desollamiento del santo, por Ribera, fue realizado en técnica del aguafuerte, y ostenta el siguiente pie de grabado: "dedico mis obras y esta estampa al serenisimo Principe Philiberto mi señor, en Napoles año de 1624. Iusepe de Rivera spañol". Copia del mismo original pintada por el pintor cuzqueño Marcos Falcón de Aguilar existe en la iglesia de Tinta Cuzco, Perú. ${ }^{35}$ Otra pintura del mismo asunto es un lienzo circular existente en la iglesia catedral de Sucre, Bolivia, atribuida al pintor altoperuano Melchor Pérez de Holguín. ${ }^{36}$

La devoción popular ha hecho conocida una valiosa pintura del apóstol San Judas Tadeo que se muestra en un altar dedicado especialmente al santo, en la nave lateral de la iglesia de la Merced en Guatemala. Ella reproduce un grabado del artista barroco italiano Juan Bautista Piazzeta (1682-1754). El lienzo en referencia al parecer pertenece a la serie de pinturas de la colección del apostolado que muestra Ia iglesia en sus muros, y en la cual falta precisamente el lienzo de San Judas. La serie del apostolado es atribuida por el arzobispo-historiador García Peláez a José Valladares, pintor de alguna fama, que floreció en Guatemala a mediados del siglo Xvirr. ${ }^{87}$

83 Kelemen, op. cit., p. 114. El artista J. Óscar Barrientos C., me ha informado que en Siquinala, Escuintla, Guatemala, existe una pequeña talla de este tema, firmada por Juan Perales.

34 Sebastián, op. cit., p. 42, véase también la lámina entre pp. 40-41.

35 José de Mesa y Teresa Gisbert, Historia de la pintura cuzqueña, Instituto de Arte Americano e Investigaciones Estéticas, Universidad de Buenos Aires, Facultad de Arquitectura y Urbanismo, Buenos Aires, 1962, figura 68.

36 José de Mesa y Teresa Gisbert de Mesa, "Un pintor colonial boliviano: Melchor Pérez de Holguín", Arte en América y Filipinas, $n$, Universidad de Sevilla, Sevilla, 1953, pp. 163-165, figuras 61-62.

37 Francisco de Paula García Peláez, Memorias para la historia del antiguo reino de Guatemala, Biblioteca "Payo de Rivera", I, Guatemala, 1943, p. 218. 
Una búsqueda exhaustiva podría establecer más huellas de las aportaciones del grabado europeo en el arte de la Guatemala de los días coloniales. La limitación de espacio en la publicación que generosamente acoge este trabajo, y la falta de complementación de otras pruebas por parte nuestra, en especial la dificultad en la obtención del correspondiente material fotográfico, disminuyen el logro de este empeño, pero consideramos que con este estudio se abre una brecha que debe ensancharse con mayor hondura y detenimiento. 